\title{
Postoperative antibiotic prophylaxis in total hip and knee arthroplasty: a systematic review and meta-analysis of randomized controlled trials
}

\author{
Patrick Thornley BHSc, Nathan Evaniew MD, Michael Riediger MD, Mitchell Winemaker MD, \\ Mohit Bhandari MD PhD, Michelle Ghert MD
}

\section{Abstract}

Background: Postoperative antibiotic prophylaxis is currently the standard of care for patients undergoing total hip and knee arthroplasty. We evaluated the evidence for this practice in the reduction of surgical-site infections.

Methods: We systematically searched MEDLINE, Embase and the Cochrane Library for randomized controlled trials (RCTs) published up to Aug. 15, 2014. We included all RCTs that compared postoperative antibiotic prophylaxis with postoperative placebo or no treatment in patients undergoing primary total hip or knee arthroplasty for osteoarthritis. We combined outcomes for surgical-site infection using a random-effects model and quantified heterogeneity using the $\chi^{2}$ test and the $I^{2}$ statistic. We assessed the overall quality of the evidence according to the Grading of Recommendations Assessment, Development and Evaluation (GRADE) approach.

Results: We identified 4 RCTs $(n=4036)$ that met the inclusion criteria. Surgical-site infections occurred in 3.1\% (63/2055) of patients in the prophylaxis group and $2.3 \%(45 / 1981)$ in the control group. Postoperative prophylaxis did not reduce the rate of surgical-site infections compared with placebo (risk difference $0.01,95 \%$ confidence interval 0.00 to $0.02 ; l^{2}=26 \%$ ). This result was robust to sensitivity testing for losses to follow-up. According to the GRADE approach, the overall quality of evidence was very low.

Interpretation: The available evidence did not show efficacy of postoperative antibiotic prophylaxis for the prevention of surgical-site infections in patients undergoing total hip or knee arthroplasty. Multicentred RCTs are likely to have an important impact on the confidence in the effect estimate and to change the estimate itself.

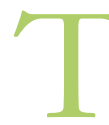
otal hip arthroplasty and total knee arthroplasty represent 2 of the most effective surgical interventions for the improvement of patient quality of life and return to function. ${ }^{1}$ Currently in the United States, more than 1 million primary total joint prostheses (mostly hip and knee) are implanted annually. ${ }^{2}$ Estimates indicate that the demand for primary total knee arthroplasty alone will exceed 3.4 million in the US annually by the year 2030. ${ }^{3}$ Maximizing efficiency and efficacy of total hip and knee arthroplasty procedures, while minimizing adverse events and costs, are currently priorities among the orthopedic surgery and medical communities alike. ${ }^{4}$

Postoperative surgical-site infection is a serious complication of total hip and knee arthroplasty, adversely affecting patients while consuming extensive hospital resources. ${ }^{4,5}$ The annual incidence of surgical-site infection is estimated to be $1 \%-2 \%$ among patients undergoing total knee arthroplasty and $0.4 \%-2.5 \%$ among those undergoing total hip arthroplasty. ${ }^{1,2}$ The cost of a single surgical-site infection associated with total joint arthroplasty represents an average 4-fold increase in cost compared with the primary procedure, with an estimated average cost of US\$50 000 per infection. ${ }^{1,4}$ As the

Competing interests: Mohit Bhandari has received consultant fees from Smith \& Nephew, Stryker, Amgen, Zimmer, Moximed, Bioventus, Merck, Eli Lilly and Sanofil, and grants from Smith \& Nephew, DePuy, Eli Lilly, Bioventus, Stryker, Zimmer and Amgen. Michelle Ghert has received consultant fees from Wright Medical, and grants from the Canadian Institutes of Health Research and the Canadian Cancer Society. No other competing interests were declared.

This article has been peer reviewed.

Correspondence to: Michelle Ghert, ghert@hhsc.ca

CMAJ Open 2015. DOI:10.9778/cmajo.20150012 
number of primary procedures grows, the burden of surgicalsite infections is expected to increase accordingly. ${ }^{5,6}$

Strategies aimed at reducing the incidence and prevalence of surgical-site infections after primary total hip and knee arthroplasty are well documented. ${ }^{7,8}$ The use of antibiotic prophylaxis (both intraoperatively and postoperatively) is accepted as the gold standard in orthopedic practice and is recommended by the most widely accepted consensusbased guidelines. ${ }^{9-11}$ The duration of postoperative antibiotic prophylaxis varies somewhat across these guidelines, from no longer than 24 hours to no longer than 36 hours (Appendix 1, available at www.cmajopen.ca/content/3/3/ E338/suppl/DC1).

We conducted a systematic review and meta-analysis to evaluate the evidence for postoperative antibiotic prophylaxis in the reduction of surgical-site infections among patients undergoing primary total hip or knee arthroplasty.

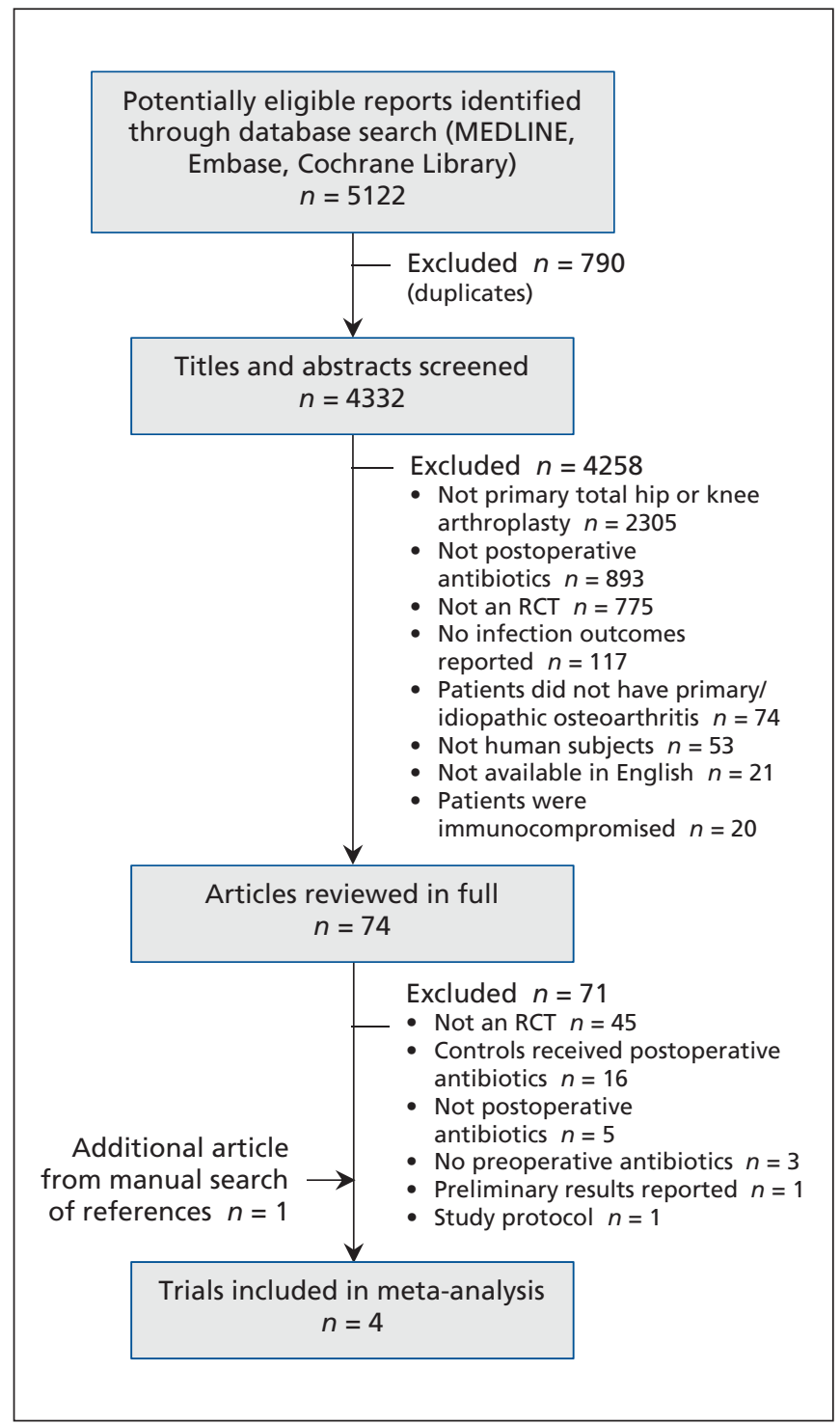

Figure 1: Selection of randomized controlled trials for inclusion in the analysis. $\mathrm{RCT}$ = randomized controlled trial.

\section{Methods}

We followed the protocol outlined in the Cochrane Handbook for Systematic Reviews of Interventions. ${ }^{12}$ We report our findings in accordance with the Preferred Reporting Items for Systematic Reviews and Meta-Analyses (PRISMA) statement. ${ }^{13}$

\section{Data sources and study selection}

We searched MEDLINE (1946 to present), Embase (1974 to present) and the Cochrane Library (no date limit) for articles published up to and including Aug. 15, 2014. Subject headings and subheadings were used in various combinations, and supplemented with free text to increase sensitivity. Details of the search strategy are available in Appendix 2 (available at www.cmajopen.ca/content/3/3/E338/suppl/DC1). In addition, we manually searched the reference lists of all included studies, consulted with experts and used the "related articles" feature in PubMed to identify additional articles.

Two of us (P.T. and N.E.), who were not blinded to the study authors or publication information (journal and date of publication), independently screened all titles and abstracts for eligibility; discrepancies were resolved through consensus.

We included all randomized controlled trials (RCTs) published in English that compared postoperative antibiotic prophylaxis with placebo or no treatment in patients undergoing primary total hip or knee arthroplasty for osteoarthritis. We included hip and knee arthroplasty because both are managed the same clinically with 24 hours of postoperative antibiotics. We excluded observational studies to focus on studies with the lowest risk of bias. ${ }^{14} \mathrm{We}$ also excluded studies if patients had baseline immunocompromised status or inflammatory arthritis or were undergoing revision procedures, studies of non-human subjects and studies not available in English. No restrictions were applied to agent, dose or duration of postoperative antibiotic prophylaxis.

\section{Data extraction and quality assessment}

Data were extracted from the trials by one of us (P.T.) and verified for accuracy by a second reviewer (N.E.) using piloted data-extraction forms. The following data were extracted: year of publication, country, sample size, mean duration of followup and losses in each study arm, mean age, sex proportions, intervention-group protocol, control-group protocol, and rates of surgical-site infection. Surgical-site infections included superficial and deep incisional infections, and deep organspace surgical-site infections. ${ }^{15}$ Other infections such as urinary tract infections and pneumonia were not included because they are not directly related to the surgical procedure.

Two of us (P.T. and N.E.) independently assessed the following parameters for risk of bias of each study using the Cochrane risk-of-bias tool: ${ }^{16}$ sequence generation; allocation concealment; blinding of participants, personnel and outcome assessors; management of incomplete outcome data; selective outcome reporting; and other sources of bias. All discrepancies were resolved through consensus.

Two of us (N.E. and M.G.) independently assessed the quality of the evidence from the RCTs according to the 
Grading of Recommendations Assessment, Development and Evaluation (GRADE) approach. ${ }^{17}$ Discrepancies were resolved through consensus. Data from RCTs are considered to be high-quality evidence, but they can be rated down according to risk of bias, imprecision, inconsistency, indirectness or publication bias. ${ }^{18}$ Data from trials of moderate quality could be rated up according to large effect or dose-response, or if all plausible biases would not undermine the conclusions.

\section{Data synthesis}

We calculated interobserver agreement for the assessments of study eligibility using the Cohen $\kappa$ coefficient and interpreted the $\kappa$ values according to Landis and Koch as poor ( $\kappa$ value 0$)$, slight (0.01-0.20), fair (0.21-0.40), moderate (0.41-0.60), substantial $(0.61-0.80)$ or almost perfect $(0.81-1.00) .{ }^{19} \mathrm{We}$ combined outcome data according to the Mantel-Haenszel method using a random-effects model. Pooled effects are presented as absolute risk differences with $95 \%$ confidence intervals (CIs). ${ }^{16}$ For patients with multiple surgical sites, we included the sites as individual patients in our analysis if they were randomized within patients. The primary analysis was an intention-to-treat analysis in which all patients were analyzed in the groups to which they were originally randomly assigned. Participants with missing data were assumed to be free of surgical-site infections in the primary analysis. Sensitivity analyses were conducted in which participants with missing data were assumed to have surgical-site infections or were excluded if losses were reported for each treatment arm.

We quantified heterogeneity using the $\chi^{2}$ test for heterogeneity and the $I^{2}$ statistic. A priori subgroup hypotheses to explain high heterogeneity included differences in agent, dose or duration of postoperative antibiotic prophylaxis. All tests of significance were 2 -tailed, and $p$ values of less than 0.05 were considered significant. Kappa values were computed using IBM SPSS version 21. The forest plot and risk-of-bias figures were created with the use of Review Manager 5.2 (Nordic Cochrane Centre, Cochrane Collaboration). We planned to conduct a funnel plot to test for publication bias, but it was omitted given the lack of interpretability associated with small numbers of included studies. ${ }^{12}$

\section{Results}

Our search strategy identified 5122 potentially relevant studies (Figure 1). After screening the titles and abstracts and removing duplicates, we reviewed 74 articles in full. We excluded 71 and added 1 article identified through the manual bibliography search, which left 4 RCTs for the meta-analysis. ${ }^{20-23}$ Interobserver agreement between the reviewers for study eligibility was fair $(\kappa=0.59)$.

Characteristics of the studies are summarized in Table 1. The mean age of the participants was 69 years in 3 trials, ${ }^{21-23}$ and an age range of $23-88$ was reported in the fourth trial. ${ }^{20}$ Most (79\%) of the patients were women in the 3 trials that reported sex. ${ }^{21-23}$ In one trial, 108 patients were randomly assigned to receive $1 \mathrm{~g}$ of nafcillin or cefazolin intravenously every 6 hours for 48 hours postoperatively versus 103 given no treatment postoperatively. ${ }^{20}$ In another trial, 338 patients were randomly assigned to received $1 \mathrm{~g}$ of teicoplanin intravenously (or a comparable prophylactic agent at the 2 other contributing centres) for 96 to 144 hours postoperatively versus 278 patients given no treatment postoperatively. ${ }^{21}$ In the other

Table 1: Characteristics of randomized controlled trials included in the meta-analysisof postoperative antibiotic prophylaxis to prevent surgical-site infections following primary total joint arthroplasty

\begin{tabular}{|c|c|c|c|c|c|c|c|}
\hline Study & Country & $\begin{array}{l}\text { No. of } \\
\text { patients/ } \\
\text { total joints }\end{array}$ & $\begin{array}{c}\text { Mean } \\
\text { follow-up, } \\
\text { yr }\end{array}$ & $\begin{array}{c}\text { Mean age, } \\
\mathrm{yr}\end{array}$ & $\%$ male & Intervention group & Control group \\
\hline $\begin{array}{l}\text { Heydemann } \\
\text { et al., }{ }^{20} 1986\end{array}$ & United States & $211 / 211$ & 1 & $\begin{array}{l}\text { Age range: } \\
23-88 \\
\text { (mean NR) }\end{array}$ & NR & $\begin{array}{l}\text { Eight } 1 \text {-g IV boluses of } \\
\text { nafcillin or cefazolin every } \\
6 \text { h until } 48 \mathrm{~h} \\
\text { postoperatively }(n=108)\end{array}$ & $\begin{array}{l}\text { No } \\
\text { postoperative } \\
\text { treatment } \\
(n=103)\end{array}$ \\
\hline $\begin{array}{l}\text { Kanellakopoulou } \\
\text { et al., }{ }^{21} 2009\end{array}$ & Greece & $616 / 616$ & 2 & 69 & 23 & $\begin{array}{l}\text { For all } 3 \text { study centres, } \\
\text { antibiotic prophylaxis } \\
\text { continued postoperatively } \\
\text { for } 4-6 \mathrm{~d} \text { (antibiotic, dose, } \\
\text { frequency and duration of } \\
\text { physician's choosing; } \\
\text { specifics NR) }(n=338)\end{array}$ & $\begin{array}{l}\text { No } \\
\text { postoperative } \\
\text { treatment } \\
(n=278)\end{array}$ \\
\hline $\begin{array}{l}\text { Ritter et al., } \\
1989\end{array}$ & United States & $196 / 196$ & 1 & 66 & 37 & $\begin{array}{l}\text { Three } 0.75-\mathrm{g} \text { IV boluses } \\
\text { of cefuroxime every } 8 \mathrm{~h} \\
\text { postoperatively for } 24 \mathrm{~h} \\
(n=98)\end{array}$ & $\begin{array}{l}\text { No } \\
\text { postoperative } \\
\text { treatment } \\
(n=98)\end{array}$ \\
\hline $\begin{array}{l}\text { Wymenga et al., }{ }^{23} \\
1991\end{array}$ & Netherlands & $2892 / 3013$ & 1 & 69 & 21 & $\begin{array}{l}0.75-\mathrm{g} \text { IV cefuroxime } 8 \mathrm{~h} \\
\text { and } 16 \mathrm{~h} \text { postoperatively } \\
\text { ( } n=1511 \text { joints) }\end{array}$ & $\begin{array}{l}\text { No } \\
\text { postoperative } \\
\text { treatment } \\
(n=1502 \text { joints) }\end{array}$ \\
\hline
\end{tabular}


2 trials, a total of 1609 patients were randomly assigned to receive $1.5 \mathrm{~g}$ of cefuroxime intravenously every 8 hours for a total of 16 hours $(n=1511)$ or 24 hours $(n=98)$ postoperatively versus 1600 patients given no postoperative prophylaxis. ${ }^{22,23}$ Patients in all of the trials received preoperative or intraoperative antibiotic prophylaxis, or both.

Infections were diagnosed on the basis of a set of positive intraoperative cultures on revision surgery ( 4 trials $)^{20-23}$ or a positive culture of purulent exudate from a draining sinus or hematoma (2 trials). ${ }^{21,23}$ In addition, the presence of $a n y^{21}$ or deep $^{23}$ purulent discharge from the surgical site was considered an important marker of surgical-site infection. Furthermore, in one trial, ${ }^{23}$ the following 4 clinical findings were

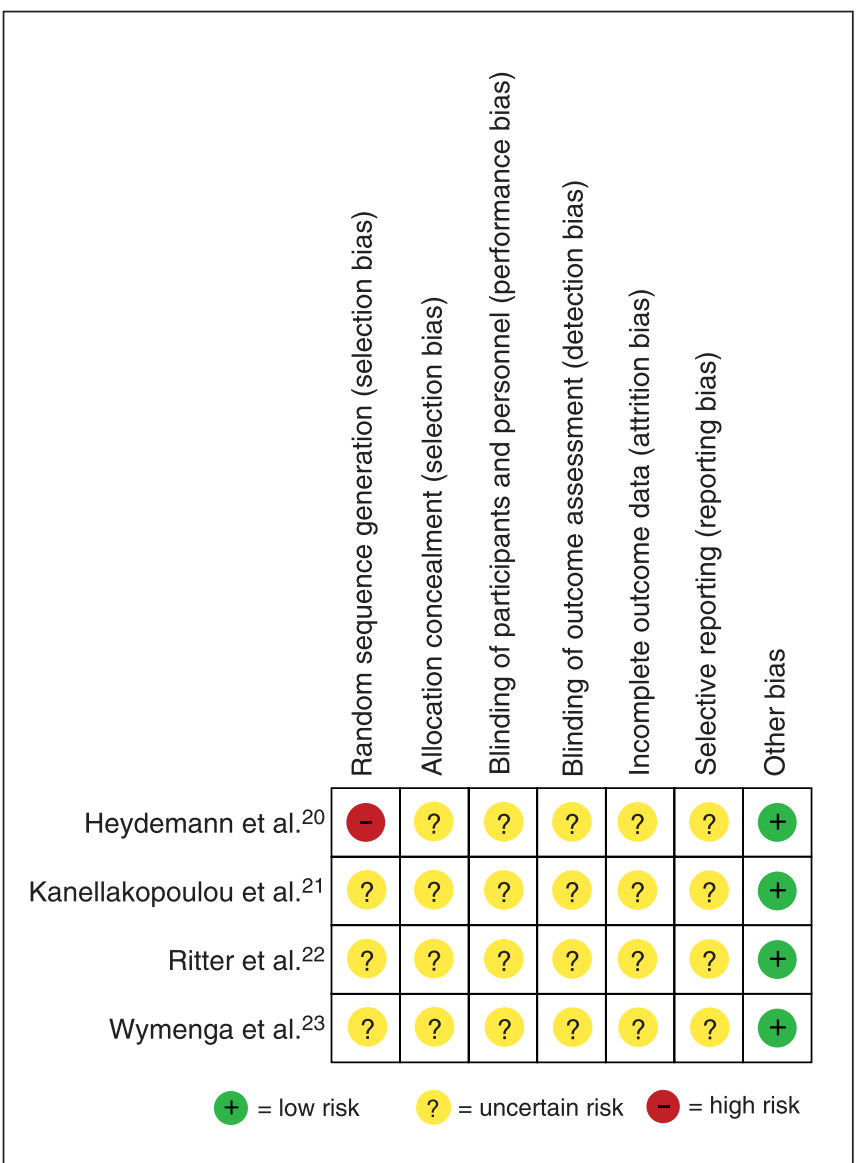

Figure 2: Appraisal of risk of bias of the included trials using the Cochrane risk-of-bias tool. ${ }^{16}$ considered in the diagnosis of a surgical-site infection: 5-day persistent fever, pain on palpation, elevated inflammatory markers (erythrocyte sedimentation rate ["20 $\mathrm{mm}$ above the pre-operative value or $>35 \mathrm{~mm}$ ") and C-reactive protein ["an increased C-reactive protein"]) or radiologic findings of periosteal reaction or progressive bone resorption. The mean follow-up varied from 12 months to 24 months, and the proportion of patients with missing data in each trial varied from $0 \%$ to $8.4 \%$.

All 4 studies were determined to have an unclear risk of bias for each of allocation concealment, blinding of participants, personnel and outcome assessors, incomplete outcome data, and selective outcome reporting (Figure 2). One study was found to be of high risk of bias for sequence generation. ${ }^{20}$ In the GRADE assessment, both reviewers rated down the quality of evidence from the 4 trials from high to very low based on (a) unclear risk of bias, (b) imprecision due to few outcome events and (c) inconsistency due to residual unexplained heterogeneity (Table 2). According to the GRADE approach, very-low-quality evidence indicates that we have very little confidence in the effect estimate, and the true effect is likely substantially different from the estimate of effect. ${ }^{19}$

\section{Incidence of surgical-site infection}

All 4 trials $(n=4036)$ reported the incidence of surgical-site infection at a minimum of 1-year follow-up. Surgical-site infections were reported in $63(3.1 \%)$ of the 2055 patients given postoperative antibiotic prophylaxis and in 45 (2.3\%) of the 1981 in the no-treatment group. The pooled estimate showed that postoperative antibiotic prophylaxis did not significantly reduce the rate of surgical-site infections (risk difference $0.01,95 \%$ CI 0.00 to 0.02 ; heterogeneity $I^{2}=26 \%$ ) (Figure 3 ). This result was robust to sensitivity analyses in which patients with missing data were either assumed to have surgical-site infections (risk difference $0.01,95 \%$ CI 0.00 to 0.02 ) or were excluded (risk difference $0.01,95 \%$ CI 0.00 to 0.02 ). Subgroup tests to explain residual heterogeneity based on differences in agent, dose or duration of postoperative antibiotic prophylaxis were not possible owing to the small number of eligible studies.

\section{Interpretation}

The available evidence from 4 trials did not show efficacy of postoperative antibiotic prophylaxis for the prevention of surgical-site infections in patients undergoing total hip or

Table 2: Grading of Recommendations Assessment, Development and Evaluation (GRADE) summary of findings

\begin{tabular}{|lccc|}
\hline Outcome & $\begin{array}{c}\text { No. of participants (studies); } \\
\text { length of follow-up }\end{array}$ & Quality of evidence (GRADE) & Anticipated effects \\
\hline $\begin{array}{l}\text { Incidence of surgical-site } \\
\text { infections }\end{array}$ & 4036 (4 trials); follow-up $\leq 2 \mathrm{yr}$ & $\begin{array}{l}\text { Very low (owing to risk of bias, } \\
\text { imprecision and inconsistency) }\end{array}$ & $\begin{array}{l}\text { The pooled absolute risk difference } \\
\text { for surgical-site infections between } \\
\text { postoperative antibiotic prophylaxis } \\
\text { and placebo or no treatment was } \\
0.01(95 \% \mathrm{Cl} 0.00 \text { to } 0.02)\end{array}$ \\
\hline Note: $\mathrm{Cl}=$ confidence interval. & & \\
\hline
\end{tabular}




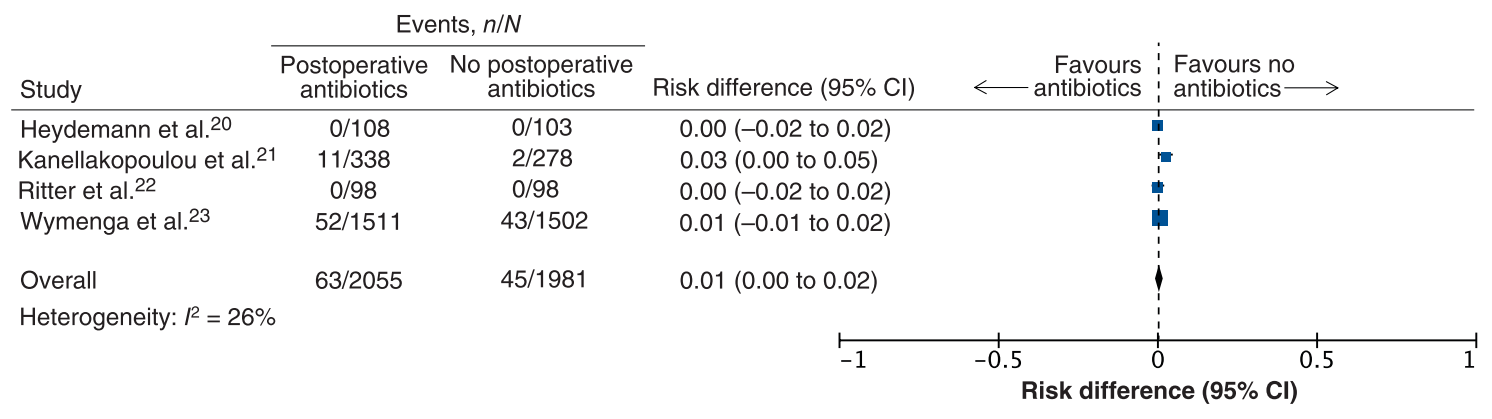

Figure 3: Pooled analysis of the effect of postoperative antibiotic prophylaxis versus placebo or no treatment for the prevention of surgical-site infections in patients undergoing total hip or knee arthroplasty reported in randomized controlled trials. A risk difference of less than zero indicates a positive effect of postoperative antibiotic prophylaxis. $\mathrm{Cl}=$ confidence interval.

knee arthroplasty. In addition, the overall quality of the evidence was very low owing to risk of bias, inconsistency and imprecision.

The rationale and evidence for pre- and intraoperative antibiotic prophylaxis for total hip and knee arthroplasty is well established. ${ }^{7,8,24-30}$ The dosages provide therapeutic serum antibiotic levels for prophylaxis while the surgical wound is open. However, debate persists over the duration of postoperative prophylaxis., ${ }^{7,31}$ The largest expert-panel consensus meeting on antibiotic prophylaxis for primary total hip and knee arthroplasty was the International Consensus Meeting on Periprosthetic Joint Infection. ${ }^{32}$ The resulting document represents a large-scale 400-member expert panel consensus report recommending the administration of antibiotic prophylaxis no less than 1 hour preoperatively, consistent with previous literature. ${ }^{7,824-30}$ Furthermore, the report achieved consensus for limiting postoperative antibiotic prophylaxis for total joint arthroplasty at 24 hours postoperatively. ${ }^{32}$ Similarly, the Scottish Intercollegiate Guidelines Network reported consensus recommendations for antibiotic prophylaxis preoperatively and continuing for 24 hours postoperatively for orthopedic interventions involving implanted devices. ${ }^{33}$

The findings of our study coupled with reports regarding the rise in antibiotic resistance carry important implications for future research and associated guideline development. Obremsky and colleagues ${ }^{34}$ advocate for an increase in RCTs and quality in orthopedic research. Although it is unlikely that a single RCT will be able to influence clinical decision-making in perioperative antibiotic prophylaxis for total joint surgery, an increase in the volume of methodologically rigorous, highquality RCTs will ensure the continued progress of evidencebased guidelines.

\section{Limitations}

We did not include trials for which the full text was unavailable in English. However, Moher and colleagues ${ }^{35}$ reported that language restrictions do not appear to bias conventional intervention estimates. We did not perform a detailed search of non-peer-reviewed literature, and it remains equally possible that abstracts of unpublished negative studies or forthcoming randomized trials were not identified. ${ }^{36}$
All outcome events reported in the included trials were based on the clinical interpretation of each trial investigator. Given the difficulties associated with the diagnosis of surgicalsite infections in total joint arthroplasty, reports of surgical-site infections in the trials may have been subjective or non-standardized. ${ }^{37}$ Diagnosis of periprosthetic surgical-site infections is challenging, and there is much debate among clinicians regarding diagnostic criteria. ${ }^{32,38-40}$ Much of what currently informs an orthopedic surgeon's clinical decision-making stems from experience and judgment. ${ }^{32}$ Our study is thus limited by non-standardized outcome assessments across the included trials.

\section{Conclusion}

The available evidence did not show efficacy of postoperative antibiotic prophylaxis for the prevention of surgical-site infections in patients undergoing total hip or knee arthroplasty. According to the GRADE approach, the overall quality of the evidence was very low. Further research will likely have an important impact on confidence in the estimate of effect and will likely change the estimate itself. Given the low event rate and the many factors that can contribute to surgical-site infections in total joint arthroplasty, large, multicentre RCTs will be required to provide evidence to support the use of postoperative antibiotic prophylaxis for the prevention of surgicalsite infections.

\section{References}

1. Illingworth KD, Mihalko WM, Parvizi J, et al. How to minimize infection and thereby maximize patient outcomes in total joint arthroplasty: a multicenter approach: AAOS exhibit selection. 7 Bone foint Surg Am 2013;95:e50.

2. Voigt J, Mosier M, Darouiche R. Antibiotics and antiseptics for preventing infection in people receiving primary total hip and knee prostheses: a systematic review and meta-analysis of randomized controlled trials. Antimicrob Agents Chemother 2015; pii: AAC.01331-15 [Epub ahead of print].

3. Nikolaou VS, Chytas D, Babis GC. Common controversies in total knee replacement surgery: current evidence. World 7 Orthop 2014;5:460-8.

4. Lindsay W, Bigsby E, Bannister G. Prevention of infection in orthopaedic joint replacement. 7 Perioper Pract 2011;21:206-9.

5. Poultsides LA, Liaropoulos LL, Malizos KN. The socioeconomic impact of musculoskeletal infections. F Bone Foint Surg Am 2010;92:e13.

6. Kurtz SM, Lau E, Schmier J, et al. Infection burden for hip and knee arthroplasty in the United States. 7 Arthroplasty 2008;23:984-91.

7. de Beer J, Petruccelli D, Rotstein C, et al. Antibiotic prophylaxis for total joint replacement surgery: results of a survey of Canadian orthopedic surgeons. Can 7 Surg 2009;52:E229-34. 
8. Swierstra BA, Bijlsma JW, de Beer JJ, et al.; Dutch Medical Association. Guideline diagnostics and treatment of osteoarthritis of the hip and knee. Ned Tijdschr Geneeskd 2009;153:B39.

9. Information statement: recommendations for the use of intravenous antibiotic prophylaxis in primary total joint artbroplasty. Rosemount (IL): American Academy of Orthopaedic Surgeons/American Association of Orthopaedic Surgeons; 2004. Available: www. aaos.org/about/papers/advistmt/1027.asp (accessed 2014 Sept. 9).

10. Primary total hip replacement: a guide to good practice. London: British Orthopaedic Association; 2006. Available: http://almacen-gpc.dynalias.org/publico/Total\%20 Hip\%20Replacement\%20BOA\%202007.pdf (accessed 2014 Sept. 9).

11. Total hip joint arthroplasty: Good practice guidelines. Wellington (New Zealand): New Zealand Orthopaedic Association; 2014. Available: http://nzoa.org.nz/ system/files/total_hip_replacement_good_practice_guidelines.pdf (accessed 2014 Sept .9).

12. Higgins JPT, Green S, editors. Cochrane handbook for systematic reviews of interventions. Version 5.1.0. Oxford: Cochrane Collaboration; 2011. Available: www.handbook.cochrane.org (2014 Dec. 9).

13. Moher D, Liberati A, Tetzlaff J, et al. PRISMA Group. Preferred reporting items for systematic reviews and meta-analyses: the PRISMA statement. 7 Clin Epidemiol 2009;62:1006-12.

14. Hoppe DJ, Schemitsch EH, Morshed S, et al. Hierarchy of evidence: where observational studies fit in and why we need them. 7 Bone foint Surg Am 2009;91(Suppl 3):2-9.

15. Definition of surgical site infection. Atlanta: US Centers for Disease Control and Prevention; 2014. Available: www.cdc.gov/nhsn/PDFs/pscManual/9pscSSIcurrent. pdf (accessed 2014 Aug. 17).

16. Higgins JPT, Altman DG, Gøtzsche PC, et al. The Cochrane Collaboration's tool for assessing risk of bias in randomized trials. BM7 2011;18:343.

17. Guyatt $\mathrm{G}$, Oxman $\mathrm{AD}, \mathrm{Akl} \mathrm{EA}$, et al. GRADE guidelines: 1. Introduction: GRADE evidence profiles and summary of findings tables. 7 Clin Epidemiol 2011; 64:383-94.

18. Balshem H, Helfand M, Schünemann HJ, et al. GRADE guidelines: 3. Rating the quality of evidence. 7 Clin Epidemiol 2011;64:401-6.

19. Sim J, Wright CC. The kappa statistic in reliability studies: use, interpretation, and sample size requirements. Phys Ther 2005;85:257-68.

20. Heydemann JS, Nelson CL. Short-term preventive antibiotics. Clin Orthop Relat Res 1986;(205):184-7.

21. Kanellakopoulou K, Papadopoulos A, Varvaroussis A, et al. Efficacy of teicoplanin for the prevention of surgical site infections after total hip or knee arthroplasty: a prospective, open-label study. Int 7 Antimicrob Agents 2009; 33:437-40.

22. Ritter MA, Campbell E, Keating EM, et al. Comparison of intraoperative versus 24 hour antibiotic prophylaxis in total joint replacement. A controlled prospective study. Orthop Rev 1989;18:694-6.

23. Wymenga AB, Hekster YA, Theeuwes A, et al. Antibiotic use after cefuroxime prophylaxis in hip and knee joint replacement. Clin Pharmacol Ther 1991; 50:215-20.

24. Ponce B, Raines BT, Reed RD, et al. Surgical site infection after arthroplasty: comparative effectiveness of prophylactic antibiotics. Do surgical care improvement project guidelines need to be updated? 7 Bone foint Surg Am 2014;96:970-7.

25. Chaweewannakom U, Turajane $\mathrm{T}$, Wonsarat $\mathrm{T}$, et al. Cost analysis of perioperative antibiotic administration in total knee arthroplasty. 7 Med Assoc Thai 2012;95(Suppl 10):S42-7.

26. National Institutes of Health. NIH consensus statement on total knee replacement. NIH Consens State Sci Statements 2003;20:1-34.

27. Bratzler DW, Houck PM; Surgical Infection Prevention Guideline Writers Workgroup. Antimicrobial prophylaxis for surgery: an advisory statement from the National Surgical Infection Prevention Project. Am 7 Surg 2005;189:395-404.

28. Vardakas KZ, Soteriades ES, Chrysanthopoulou SA, et al. Perioperative anti- infective prophylaxis with teicoplanin compared to cephalosporins in orthopaedic and vascular surgery involving prosthetic material. Clin Microbiol Infect 2005; $11: 775-7$.

29. Zheng H, Barnett AG, Merollini K, et al. Control strategies to prevent total hip replacement-related infections: a systematic review and mixed treatment comparison. BM7 Open 2014;4:e003978.

30. AlBuhairan B, Hind D, Hutchinson A. Antibiotic prophylaxis for wound infections in total joint arthroplasty - a systematic review. 7 Bone foint Surg $\mathrm{Br}$ 2008;90:915-9.

31. Slobogean GP, Kennedy SA, Davidson D, et al. Single-versus multiple-dose antibiotic prophylaxis in the surgical treatment of closed fractures: a meta-analysis. 7 Orthop Trauma 2008;22:264-9.

32. Gehrke T, Parvizi J. Proceedings of the International Consensus Meeting on Periprosthetic 7oint Infection. Rolle (Switzerland): European Federation of National Associations of Orthopaedics and Traumatology; 2013. Available: www.efort org/wp-content/uploads/2013/10/Philadelphia_Consensus.pdf (accessed 2014 July 03).

33. Antibiotic prophylaxis in surgery: a national clinical guideline. Edinburgh (UK): Scottish Intercollegiate Guidelines Network; 2008. Available: www.sign.ac.uk/ pdf/sign104.pdf (accessed 2015 Aug. 25).

34. Obremskey WT, Pappas N, Atallah-Wasif E, et al. Level of evidence in orthopaedic journals. 7 Bone foint Surg Am 2005;87:2632-8.

35. Moher D, Pham B, Lawson MI, et al. The inclusion of reports of randomised trials published in languages other than English in systematic reviews. Health Technol Assess 2003;7:1-90.

36. Evaniew N, Khan M, Drew B, et al. Intrawound vancomycin to prevent infections after spine surgery: a systematic review and meta-analysis. Eur Spine $\mathcal{f}$ 2015;24:533-42.

37. Osmon DR, Berbari EF, Berendt AR, et al. Diagnosis and management of prosthetic joint infection: clinical practice guidelines by the Infectious Diseases Society of America. Clin Infect Dis 2013;56:1-10.

38. Toossi N, Adeli B, Rasouli MR, et al. Serum white blood cell count and differential do not have a role in the diagnosis of periprosthetic joint infection. 7 Arthroplasty 2012;27(Suppl):51-4.e1.

39. Yi PH, Cross MB, Moric M, et al. The 2013 Frank Stinchfield Award: diagnosis of infection in the early postoperative period after total hip arthroplasty. Clin Orthop Relat Res 2014;472:424-9.

40. Parvizi J, Jacovides C, Zmitowski B, et al. Definition of periprosthetic joint infection: Is there a consensus? Clin Orthop Relat Res 2011;469:3022-30.

Affiliations: Faculty of Health Sciences (Thornley), Michael G. DeGroote School of Medicine; Division of Orthopaedics (Evanview, Riediger, Winemaker, Bhandari, Ghert), Department of Surgery; Department of Clinical Epidemiology and Biostatistics (Bhandari), McMaster University, Hamilton, Ont.

Contributors: All of the authors contributed to the study concept and design. Michelle Ghert, Patrick Thornley, Nathan Evanview and Michael Riediger contributed to the acquisition of data. All of the authors were involved in the analysis and interpretation of data. Patrick Thornley drafted the manuscript, and all of the authors critically revised it. All of the authors approved the final version of the manuscript to be published and agreed to act as guarantors of the work.

Supplemental information: For reviewer comments and the original submission of this manuscript, please see www.cmajopen.ca/content/1/3/ E338/suppl/DC1 